\title{
The Motion Simulation of Ham Kneading Machine and the Finite Element Analysis of Key Parts
}

\author{
Yijie Zhang ${ }^{1}$, Lingqiong Kong ${ }^{2}$, Jie Shi ${ }^{1}$, Xinwen Luo ${ }^{1}$, Huan Zou ${ }^{1}$,Yang Yu ${ }^{1, *}$ \\ ${ }^{1}$ College of Electromechanical Engineering, Yunnan Agricultural University, \\ Kunming 650201, China \\ ${ }^{2}$ College of Hydraulic Engineering, Yunnan Agricultural University, Kunming \\ 650201, China \\ Corresponding Author: Yang Yu,yj_nd@sina.com
}

\begin{abstract}
Yunnan traditional dry-cured ham has been mainly produced by manual process and lacks support of machining equipment, which would lead to many problems such as unsteady quality and low productivity. To improve the quality of Yunnan ham, a ham kneading machine was developed to knead and massage fresh ham. The machine utilizes the combined effect of cams striking and rollers rolling to replace the traditional manual processing method. A three-dimensional virtual simulation study was carried out based on the SolidWorks design platform so as to further understand the motion mechanism and structural strength of the new-type machine. A three-dimensional parametric model of the ham kneading machine was established; SolidWorks Motion was used to simulate and analyze the motion and force conditions of the ham kneading process; SolidWorks Simulation was used for the static strength analysis of key parts and modal analysis of the frame. The simulation results show that: fresh ham keeps vibrating in the entire kneading process; the kneading force varies with the ham shape and cam phase with its peak value of $994 N$; the assurance coefficients of roller shaft and pressure shaft are respectively 3.395 and 5.148; the stress amplitudes are respectively $81.22 \mathrm{Mpa}$ and $53.56 \mathrm{Mpa}$, which are both smaller than the yield limits of the structures, indicating the structural strength is adequate; the frequencies of the first four order modals of the frame are $30 \mathrm{~Hz}, 32 \mathrm{~Hz}, 38 \mathrm{~Hz}$ and $50 \mathrm{~Hz}$, all avoiding the external excitation frequency generated by the kneading action of cams and motor operation, thus preventing resonance effectively. The research provides an important reference for subsequent prototype test and structure optimization of ham kneading machines.
\end{abstract}

Keywords: Ham; Kneading; Motion; Finite Element Analysis.

\section{Introduction}

Known in the world, Yunnan Ham is one of China's three most famous dry-cured ham brands, enjoying equal popularity with Jinhua Ham and Rugao Ham. However, Yunnan Ham production has been mainly dependent on workers'manual skills through the years, and this production pattern would lead to many problems such as unsteady quality, excessively high salinity and low productivity. In order to solve the abovementioned problems, advanced ham production technology in foreign countries are studied, such as the famous Italian Parma Ham. According to the studies, foreign countries have adopted ham tumbling and massaging machinery in the production of dry-cured hams, which can tumble the whole bone-in hams, clear the blood left in the vessels of fresh hams, accelerate salt penetration and diffusion through mechanical vibration and squeeze and thus effectively reduce the amount of salt and improve the quality[1-4]. This method is of high reference value for improving China's traditional dry-curing process. In China, some research institutes have been engaged in developing special equipment for kneading dry-cured hams. For example, Zhang Jianhao et al. 
[5]from Nanjing Agricultural University developed a rolling-kneading machine specially for curing Jinhua Ham and realized ham-copying vibration, rolling and kneading by using spatial linkage mechanism. Yu Yang et al. [6] from Yunnan Agricultural University invented the Ham Kneading Machine that was designed according to the shape and processing technics of Yunnan Ham. The article takes the self-developed new-type ham kneading machine[7-8] as its object and conducts motion analysis of the kneading process and the finite element analysis of key parts, with its results serving as important guidance for subsequent prototype test and structure optimization.

The rest of this article is organized as follows: section 2 introduces structural features of the ham kneading machine, kneading process of dry-cured ham and the SolidWorks-based virtual simulation analysis method; section 3 describes motion characteristics of the ham kneading machine during the process and presents the results of finite element analysis of its key bearing parts; and section 4 is the conclusion and discussion.

\section{Materials and methods}

\subsection{Introduction of the Kneading Process of Dry-cured Ham}

Yunnan Ham is a brand of dry-cured hams, with its traditional production process shown in Figure1. In the curing process, kneading is an important step and mainly adopts manual process, i.e. grinding salt into powder, applying salt to fresh hams and then rubbing and kneading by hand [9-10]. By manual process, however, on the one hand the kneading strength is not enough to ensure sufficient penetration of salt, on the other hand, unsteady quality is more likely to occur due to the individual difference of workers. A method of mechanical kneading process has been proposed to substitute for the backward manual process, and it is described as follows: While being conveyed continuously, fresh hams will be kneaded and massaged mechanically, and subject to vertical vibration in the meanwhile. Scenes of traditional manual process and mechanical kneading process of dry-cured ham are respectively shown in Figure $2 \mathrm{a}$ and Figure 2b.

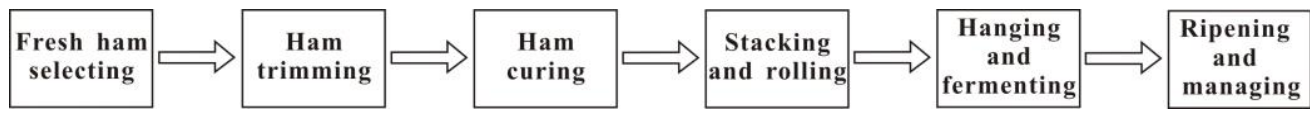

Figure 1. Flow Chart of the Kneading Process of Yunnan Ham

\subsection{The Overall Structure and Operating Principles}

Main design parameters of ham kneading machine are shown in table 1 . The machine is mainly composed of conveyor, rolling device, tensioner, motor, reducer and frame, etc. The working process of the machine is that: first, fresh hams are fed to the kneading area after being applied with salt; then they operate and vibrate up and down with the conveyor belt under the combined action of conveying rollers and cams; in the meanwhile, fresh hams are rolled and kneaded by the upper rolling device. Besides, the pressing roller subunit is subject to synchronous vertical vibration with the fresh hams under the action of spring force. In the entire kneading process, fresh hams are always contained in the copying enveloping space that is formed by the conveyor belt and upper pressure belt, preventing the fresh hams from slipping and achieving stable and reliable kneading. The machine has replaced manual kneading, realized mechanized production and ensured the quality of products. Three dimensional virtual model of the 
whole ham kneading machine and its main structure diagram are respectively shown in Figure $3 \mathrm{a}$ and Figure $3 \mathrm{~b}$.

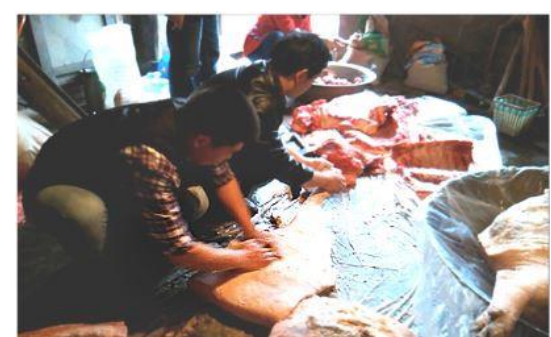

a. Traditional manual process

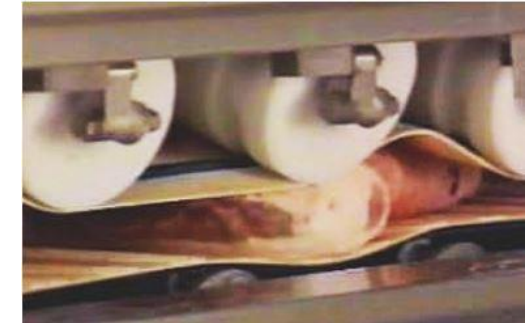

b. Mechanical kneading process

\section{Figure 2. Scenes of the Ham Kneading Process}

Table 1. Main Parameters

\begin{tabular}{cc}
\hline Items & Values \\
\hline supporting power $/ \mathrm{kw}$ & $>0.8$ \\
kneading spacing $/ \mathrm{mm}$ & $200-300$ \\
kneading width $/ \mathrm{mm}$ & $400-450$ \\
Kneading speed $/\left(\mathrm{mm} \cdot \mathrm{s}^{-1}\right)$ & $70-80$ \\
kneading strength $/ \mathrm{N}$ & $588-784$ \\
\hline
\end{tabular}

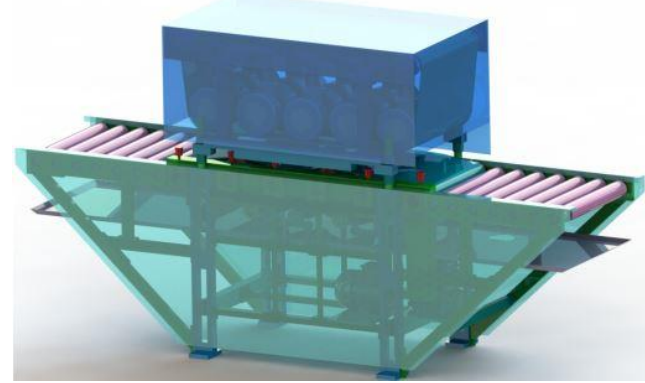

a. Three dimensional virtual model

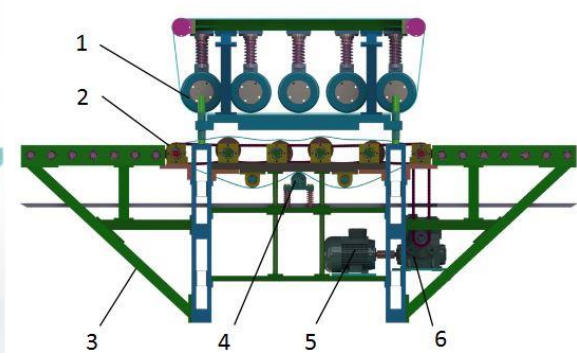

b. Main Structure Diagram

1. Rolling device 2. Conveyor 3. Frame 4 Tensioner 5.Motor 6.Reducer

Figure 3. Structure Diagram of the Ham Kneading Machine

\subsection{Key Structure and Characteristics of Ham Kneading Machine}

\section{Conveyor}

By conveyor, fresh hams on working table can be stably fed in proper order and struck by cams during the conveying process. It's mainly composed of conveying roller, camshaft, cam and chain, etc. as shown in Figure 4. 


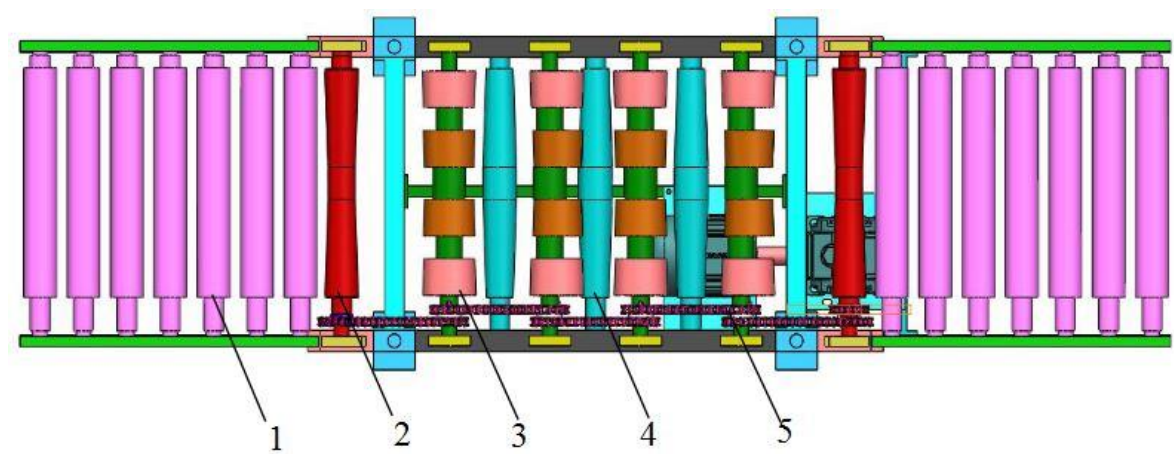

1.conveying roller 2. shaft of conveyor belt 3. cam 4. tensioner 5. chain

Figure 4. Structure Diagram of the Conveyor

Figure 4 shows: the conveyor is mainly composed of 4 camshafts, 2 shafts of conveyor belt, 3 tensioners, 5 sets of chain drive and some conveying rollers. Thereinto, there are 4 cams on each camshaft with a taper of $2^{\circ}$; two shafts of conveyor belt are driven by chains and the structure is characterized by narrow middle and wide ends so as to avoid fresh hams from slipping on both sides. Shafts of conveyor belt and camshafts are driven by chain drive so that the conveyor can reliably drive the fresh hams to overcome the rolling resistance and move forward. The four sets of cams in the middle rotate synchronously while the two shafts of conveyor belt on both sides rotate slower than the cams so that the fresh hams could be struck by the cams at a suitable frequency.

Rolling device

The main body of rolling device is mainly composed of upper pressure belt, upper pressure spring, pressing roller, pressing shaft and roller shaft with its structure shown in Figure 5.

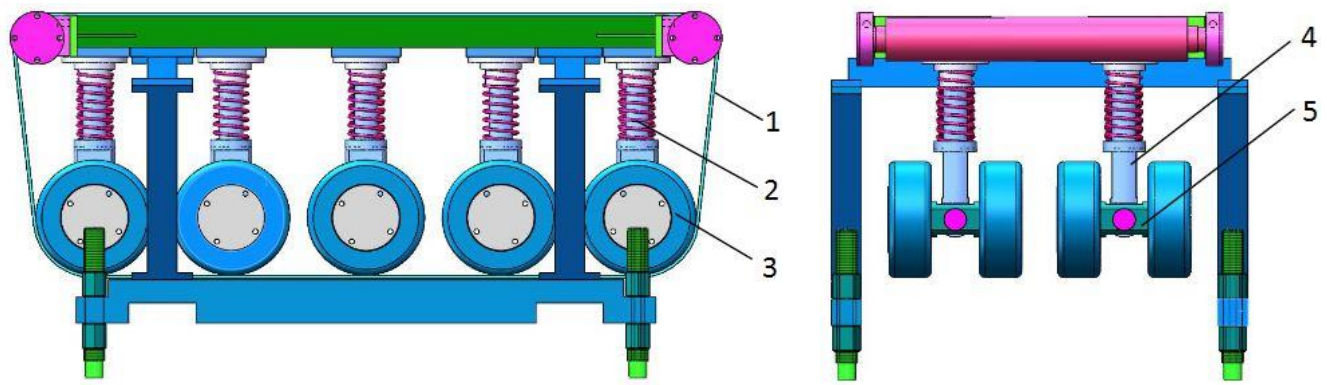

a. Front View

b. Side-face View (excluding upper pressure belt)

1. upper pressure belt

2. upper pressure spring 3. pressing roller 4. pressing shaft

5. roller shaft

Figure 5. Structure Diagram of the Rolling Device

Figure $5 \mathrm{a}$ is the front view of rolling device and Figure $5 \mathrm{~b}$ is the side-face view of rolling device excluding the upper pressure belt. As shown in the figure, the rolling device contains 5 double-row pressing roller subunits with the same structure. Each pressing roller is installed on both ends of the roller shaft and can rotate freely; upper pressure spring is set on the pressing shaft which can move up and down with the change of spring force; pressing roller pushes against fresh hams through the upper pressure spring. During the entire operation, the whole fresh hams are always enveloped by the conveyor belt and upper pressure belt so that the copying kneading is effectively realized under the combined action of cams striking and rollers rolling. 


\subsection{Motion Analysis and the Finite Element Analysis Method Based on SolidWorks}

SolidWorks Motion is a simulating tool for making virtual prototypes. By virtue of its powerful dynamic simulation core of ADAMS, it can help designers to judge whether a project could achieve the expected goal in the early stage of design. The dynamic characteristics and changing rules of kneading forces in the kneading process could be obtained through simulation and analysis. The finite element simulation analysis can comprehensively assess the safety performance and life of mechanical parts. Based on the motion simulation results, SolidWorks Simulation can directly select one or more parts that need finite element analysis in the assembly model, show the analysis results of their stress, deformation and assurance coefficient, etc. and judge whether the structural strength is adequate conveniently and quickly.

\subsection{Basic Ideas and Equations of The Modal Analysis}

Modal analysis is the technology to determine vibration mode of mechanical products structure with its basic content including natural frequency and vibration mode. The essence of the finite element modal analysis is: discrete the vibration of an elastic continuum to that of a multi-degree-of-freedom system which takes a finite number of joint displacements as generalized coordinates. Modal analysis can be used to choose reasonable structure design because it not only avoids structure resonance at work but also serves as the basis to analyze the dynamic response and other power characteristics. The differential equation of the motion of modal analysis is:

$$
[M]\{\ddot{x}\}+[K]\{x\}=0
$$

Thereinto, $[M]$ is the mass matrix, $[K]$ is the stiffness matrix, $\{x\}$ is the displacement matrix and $\{\ddot{x}\}$ is the acceleration matrix. During the free vibration, each point on the structure makes simple harmonic vibration. The joint displacement matrix and characteristic equation are as follows:

$$
\begin{array}{r}
\{x\}=\{\phi\} \sin \omega\left(t-t_{0}\right) \\
\left([K]-\omega^{2}[M]\right)\{\phi\}=0
\end{array}
$$

Thereinto, $\{\phi\}$ is the $\mathrm{n}$-th order vector, $\omega$ is the vibration frequency, $t$ is time variable and $t_{0}$ is the time constant. Solving the above equation, $n$ characteristic solutions can be obtained. Characteristic value $\omega_{n}$ is the natural frequency of the $n$-th order, characteristic vector $\phi_{n}$ is the corresponding vibration mode.

\section{Results}

\subsection{The Motion Analysis Based on SolidWorks}

Because the machine has a complex structure and consists of numerous parts and components, a simplified virtual prototype simulating the kneading process of the fresh ham passing only 3 pressing roller subunits was established (see Figure 6) on the basis of considering both computer resource and simulation rationality.

The fresh ham in the above model was also simplified on the premise that it could meet the requirements of analysis. The side curve shape was drawn according to the profile curve of Yunnan Xuanwei Ham; the angular variation of $156^{\circ}-180^{\circ}$ at the backside of the ham was neglected; the material of the ham was considered as a fiber reinforced composite [11-12]. The solid models of the conveyer belt and upper pressure belt were reduced during the simulation, and the horizontal conveying effect of the conveyer belt was obtained by setting a constant horizontal velocity for the fresh ham. To understand the motion rules in kneading process in a more detailed way, the fresh ham is roughly divided into four kneading areas named A, B, C, and D according to the 
anatomical structure of Yunnan ham. The parameters for calculation in this simulation are as follows: conveying speed: $77.6 \mathrm{~mm} / \mathrm{s}$; cam rotation speed: $75 \mathrm{r} / \mathrm{min}$; simulation duration: 4s; FPS: 30 . Figure 7 shows the images of the fresh ham's vertical velocity and acceleration.

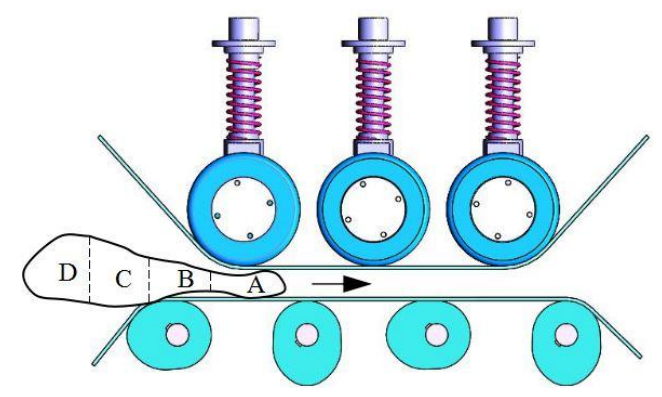

Figure 6. Simplified Virtual Prototype

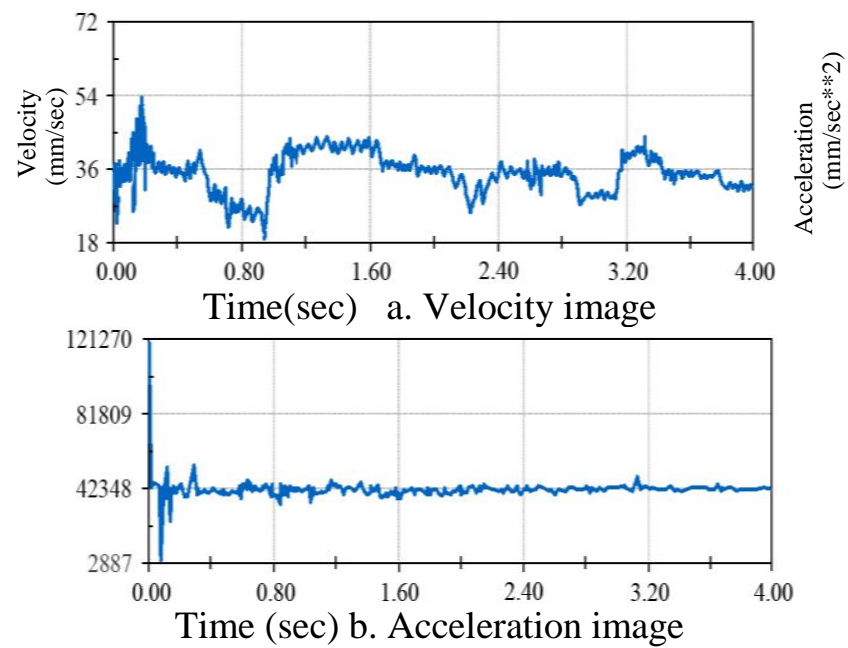

Figure 7. Images of Fresh Ham's Velocity and Acceleration

It can be seen from Figure 7 that there were fluctuations in the fresh ham's vertical velocity and acceleration and the fluctuations were smooth relatively. The fluctuation range could be even smaller if considering the elastic envelop formed by the upper pressure belt and conveyer belt. Simulation results show that the fresh ham is kneaded continuously by cams and rollers in the entire kneading process and vibrates stably and vertically. This motion helps clear the blood left in the vessels of fresh ham, make muscles and soft tissues loose and soft, and accelerate salt penetration and diffusion. The following takes the second pressing roller subunit as research object and analyzes the changing rule of the force of upper pressure spring during a complete rolling operation that lasts for $4 \mathrm{~s}$. Figure 8 shows the simulation image and Table 2 shows the explanations. 


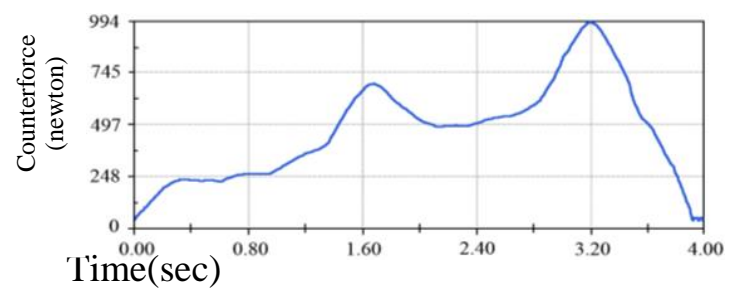

Figure 8. Image of Force Changes of Roller Pressing Spring

Table 2. Motion Analysis of Kneading Process

\begin{tabular}{ccc}
\hline Kneading time/s & Kneading area & Motion analysis \\
\hline $0-1$ & Area $\mathrm{A}$ & $\begin{array}{c}\text { The roller pressing spring turns from pre-tightening state to } \\
\text { pressing state. Because the shape variation of the fresh ham is } \\
\text { small, the spring pressure mainly changes with cam phase. }\end{array}$ \\
\hline $1-2$ & AreaB & $\begin{array}{r}\text { The spring pressure changes with variations in both the shape of the } \\
\text { fresh ham and cam phase. The kneading force is increasing } \\
\text { continuously and reaches the first peak of } 677 \mathrm{~N} \text { at } 1.7 \mathrm{~s} .\end{array}$ \\
\hline $3-4$ & Area D & $\begin{array}{c}\text { The spring pressure changes with variations in both the shape of the } \\
\text { fresh ham and cam phase. The kneading force decreases from the } \\
\text { first peak and then increases. }\end{array}$ \\
& $\begin{array}{c}\text { The spring pressure continues increasing with the increase of the } \\
\text { ham's thickness, and the kneading force reaches the second peak of } \\
\text { 994N at 3.2s. Then, the spring pressure decreases gradually and } \\
\text { returns back to the pre-tightening state after finishing the kneading } \\
\text { operation. }\end{array}$ \\
\hline
\end{tabular}

\subsection{The Key Parts Static Strength of Finite Element Analysis Based on SolidWorks}

Pressing roller subunit is a key bearing part for kneading ham and mainly composed of pressing roller, roller shaft and pressing shaft. The roller shaft and pressing shaft are slim parts and the weak link of structural strength, hence we shall know the details of stress distribution and assurance coefficient of the two parts so as to evaluate the design results. The stress cloud chart of roller shaft and pressing shaft is shown in Figure9; the assurance coefficient cloud chart of roller shaft and pressing shaft is shown in Figure10; and the strength analysis is concluded in table 3.

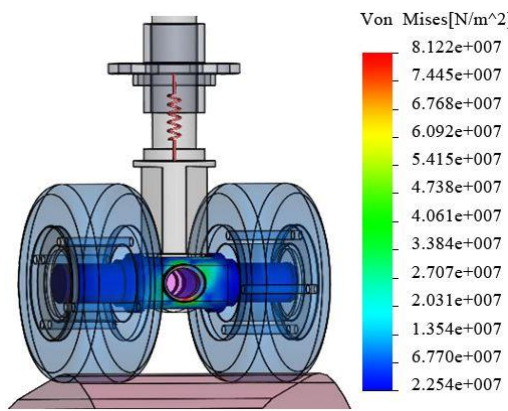

a.The stress diagram of roller shaft

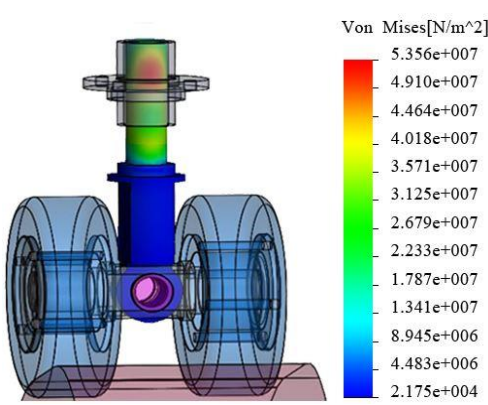

b.The stress diagram of pressing shaft

Figure 9. The Stress Cloud Chart of Roller Shaft and Pressing Shaft 

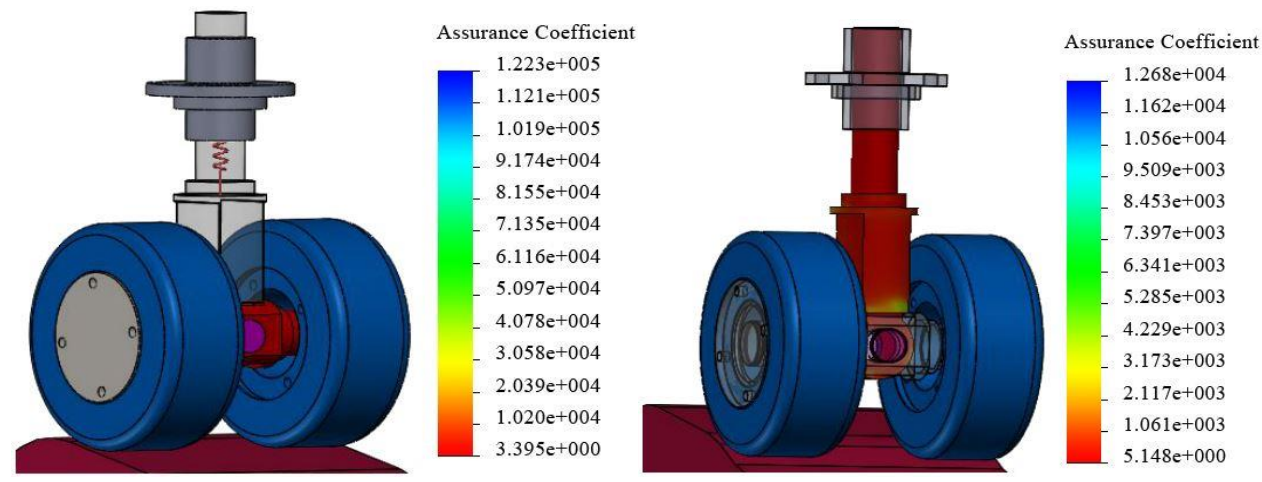

a. The assurance coefficient diagram of roller shaft b.The assurance coefficient diagram of pressing shaft

Figure 10. The Assurance Coefficient Cloud Chart of the Roller Shaft and the Pressure Shaft

Table 3. The Results of Finite Element Analysis

\begin{tabular}{cccc}
\hline & Stress Amplitude & $\begin{array}{c}\text { Min. Assurance } \\
\text { Coefficient }\end{array}$ & Conclusion \\
\hline Roller shaft & $81.22 \mathrm{Mpa}$ & 3.395 & \\
Pressure roller & $53.56 \mathrm{Mpa}$ & 5.148 & Sufficient strength \\
Yiled limit & & $275.7 \mathrm{Mpa}$ & \\
\hline
\end{tabular}

\subsection{The Modal Analysis of the Frame Based on SolidWorks}

The frame is a key load bearing part of the ham kneading machine, to which the dynamic load directly transfers, so its vibration must be considered in the design of the ham kneading machine. The frame of this machine is a welded and assembled structure made of Q235 steel, the elasticity modulus, density and Poisson's ratio of which are $210 \mathrm{Gpa}, 7850 \mathrm{~kg} / \mathrm{m} 3$ and 0.3 , respectively. The finite element modal analysis of SolidWorks Simulation provides relatively comprehensive data of the natural frequency and vibration mode of the frame structure, which can be a necessary basis for optimizing the dynamic performance of the frame structure. Generally speaking, low order vibration has great impacts on the dynamic performance of the structure, and the low order vibration mode determines the dynamic characteristics of the structure. According to the actual situation of the ham kneading machine in operation, the bottoms of the four pillars supporting the frame are fixed and bound to simulate the stationary state of the machine at work, and the first twelve order modals of the frame are extracted for making a solution and an analysis, of which the natural frequency changing curve is shown in Figure 11. The vibration mode cloud chart of the first four orders is shown in Figure 12, and the vibration mode analysis is given in Table 4.

From the above analysis, it can be seen that the modal frequencies of the frame mainly distribute within the ranges of $30 \mathrm{~Hz}-50 \mathrm{~Hz}$ and $81 \mathrm{~Hz}-99 \mathrm{~Hz}$, which are the major zones that affect the vibration characteristics of the frame; the external excitation of the ham kneading machine comes mainly from cams and the motor: the excitation frequency of cams is caused by their vibration during kneading the raw ham, and the rotating speed and excitation frequency of the cams are $75 \mathrm{r} / \mathrm{min}$ and $1.25 \mathrm{~Hz}$, respectively; the working speed and excitation frequency of the motor are $910 \mathrm{r} / \mathrm{min}$ and $15.2 \mathrm{~Hz}$. Obviously, the external excitation frequencies are smaller than $30 \mathrm{~Hz}$, which is 
the lowest order natural frequency of the frame, so the frame will not generate resonance and can achieve good dynamic performance.

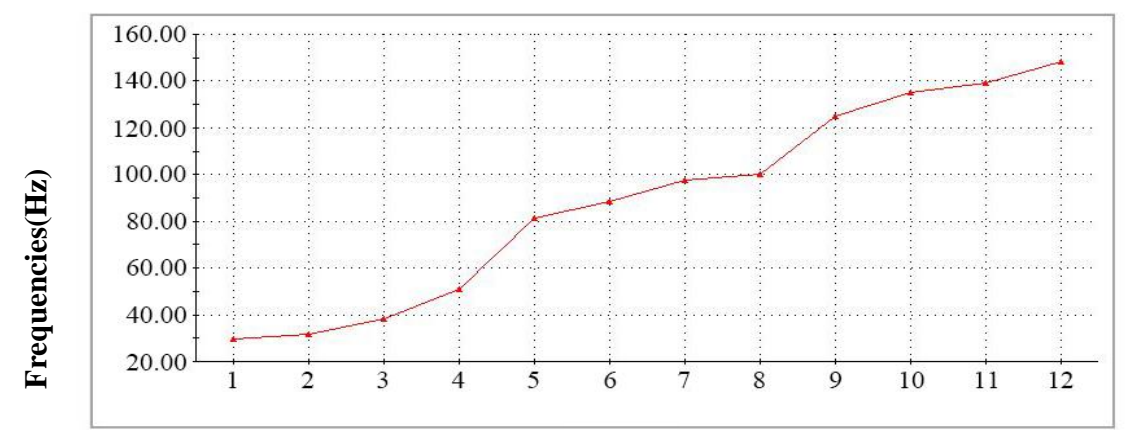

Order

Figure 11. The Natural Frequency Changing Curve Chart of the First Twelve Order Modals

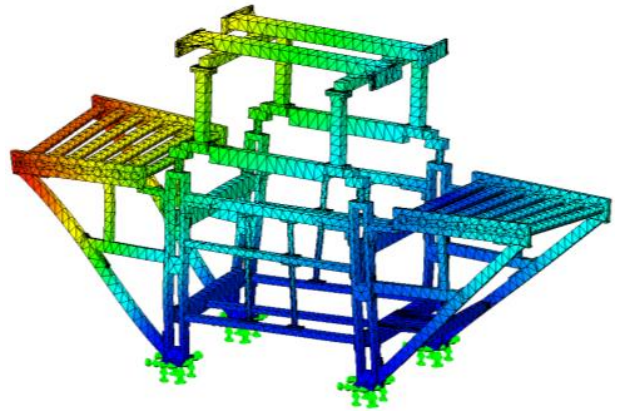

a. 1 st order $\operatorname{mode}(30 \mathrm{~Hz})$

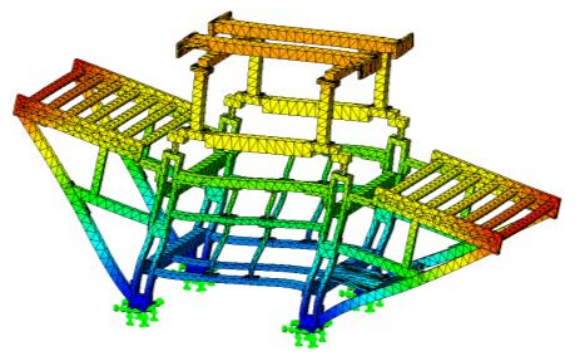

c. 3 st order mode $(38 \mathrm{~Hz})$

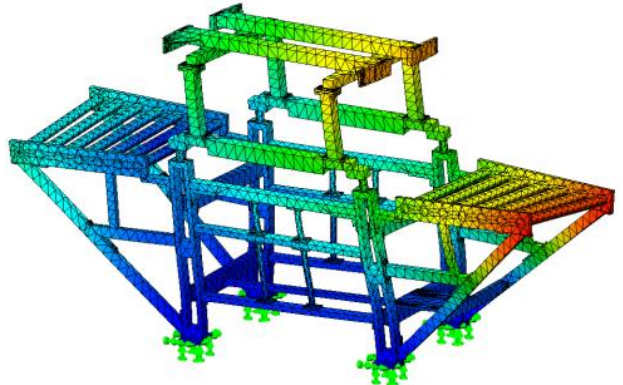

b. 2 st order mode $(32 \mathrm{~Hz})$

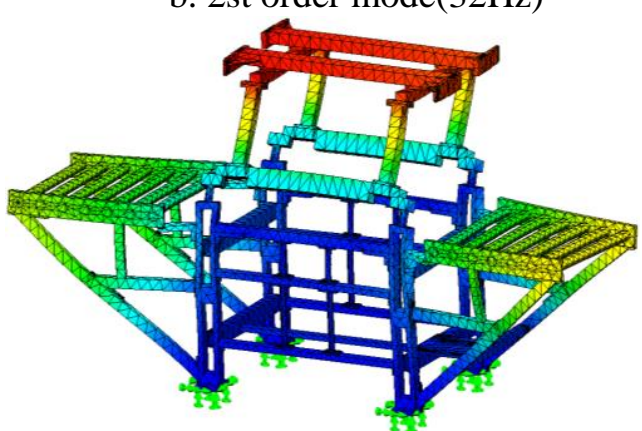

d. 4 st order mode $(50 \mathrm{~Hz})$

Figure 12. The Vibration Mode Cloud Chart of the First Four Order Modals 
Table 4. Resonance Frequency and Vibration Mode Analysis

\begin{tabular}{cccc}
\hline \multirow{3}{*}{ Order } & \multicolumn{3}{c}{ Modal calculation results } \\
\cline { 2 - 4 } & $\begin{array}{c}\text { Resonance } \\
\text { frequency }\end{array}$ & Vibration mode analysis \\
& & & \\
1 & 30 & Bending forward and backward \\
2 & 32 & Bending forward and backward \\
3 & 38 & Bending to the left and right hand sides \\
& 4 & 50 & Torsion of the whole structure \\
\hline
\end{tabular}

\section{Conclusions}

To further understand the motion mechanism of a new-type ham kneading machine and the static strength and dynamic characteristics of its key parts, the article simulates the motion state of fresh ham during kneading process based on SolidWorks Motion, conducts the finite element analysis and modal analysis of its key parts. The research conclusions are shown in the following:

As shown in the motion simulation, the machine can realize similar motion effect of manual kneading through cams striking and rollers rolling. Besides, the machine is reliable at work and simple in structure, effectively solving many problems in traditional manual kneading process.

Analyzed from the simulation curves of speed and acceleration, it can be seen that fresh hams get relatively stable vibration in the whole kneading process. The simulation image of force reflects the changing rules of kneading force under the combined effect of cam phase and ham shape with its peak of $994 \mathrm{~N}$, which is greater than the manual force of a person with a weight of $60 \mathrm{~kg}-80 \mathrm{~kg}$. So the kneading force is enough and meets the requirements.

According to the finite element analysis, the min. assurance coefficient of key parts is 3.395 and the max. stress amplitude is $81.22 \mathrm{Mpa}$, both meeting the requirements of structural strength. According to modal analysis of the frame, the first four order modal frequencies of the frame are $30 \mathrm{~Hz}, 32 \mathrm{~Hz}, 38 \mathrm{~Hz}$ and $50 \mathrm{~Hz}$, all avoiding the external excitation frequency, thus preventing resonance effectively and achieving great dynamic performance.

The virtual simulation model will be further optimized in future research so as to obtain more accurate results. In addition, experimental research on ham kneading process will be carried out in the future and the rationality of virtual simulation analysis will be verified through comparison with experimental results.

\section{Acknowledgements}

Funded Project: The research work was supported by Science and Technology Planning Project of Yunnan under Grant No. 2008LA016.

\section{References}

[1] Li Jianrong. The Comparison of technology between Jinhua ham, Parma ham, Iberian ham and Serrano ham[J]. China Condiment, (2009), 34(2): 36-39.

[2] Zeng Siwei, Hu Hongchao, You Ruiju, et al. Technological Process and Quality Control of Italy Parma Ham[J]. Journal of Anhui Agricultural Sciences, (2013), 41(24): 10110-10114. 
[3] Zhu Shangwu. Modern technology and research progresses on italian parma ham[J]. Food and Machinery, (2006), 22(2): 59-61,89.

[4] Zeng Tao. Study on the Knead-Salting Processing and Affects for the Flavor and Quality of Jinhua Ham[D]. Nanjing: Nanjing Agricultural University, (2006).

[5] Zhang Jianhao, Shen Dehong, Zhou Guanghong. Rolling and Kneading Machine for Dry-cured Hams [P]. Chinese Patent No.: 200320110876.9. (2005)-01-19.

[6] Yu Yang, Zhang Xi, Li Qi, et al. Ham Kneading Machine [P]. Chinese Patent No.: 201220600034.0. (2013)-4-17.

[7] Zhang Yijie, Li Qi, Yu Yang, et al. Research and Design of Ham Kneading Machine[J]. Journal of Yunnan Agricultural University (Natural Science), (2014), 29(3): 425-429.

[8] Hu Hongchao, Zeng Siwei, You Ruiju, et al. Modeling of Ham Kneading Machine and Force Analysis of Ham [J]. Packaging and Food Machinery, (2014), 32(4): 31-35.

[9] Liu Ning, Sun Xiyun, Ge Changrong. Yunnan Ham Processing and Its Characteristics [J]. Farm Products Processing, (2007),6(6): 18-20.

[10] Fan Jiangping,Ge Changrong, LuZhaofen, et al. Discussion of Processing Characteristics of Yunnan Ham [J].Meat Industry, (2005), 21(4): 22-24.

[11] Wang Baozhen, Hu Shisheng. A transversely isotropic constitutive model for porcine ham muscle under impact loading[J]. Explosion and Shock Waves, (2011), 31(6): 567-572.

[12] Wang Baozhen. Research on Dynamic Mechanical Properties of Soft Muscle Tissue [D]. Hefei: University of Science and Technology of China, (2009).

[13] Zhao Yun, Fan Fulei, Song Zhichao, et al. Design and simulation of inverted vegetable pot seedling transplanting mechanism with conjugate cam $[\mathrm{J}]$. Transactions of the Chinese Society of Agricultural Engineering (Transactions of the CSAE), (2014), 30(14): 8-16.

[14] Zhai Zhiping, Zhou Lei, Yang Zhongyi, et al. Analysis on vibration characteristics of throwing impeller of stalk impeller blower[J]. Transactions of the Chinese Society of Agricultural Engineering (Transactions of the CSAE), (2015), 31(4): 17-25.

[15] Liao Qingxi, Hu Xianpeng, Zhang Zhao, et al. Analysis on detaching process of detaching device and seedling pot integrity about rape transplanter[J]. Transactions of the Chinese Society of Agricultural Engineering (Transactions of the CSAE), (2015) 31(16): 22-29.

[16] Zhu Zhongxiang, Yue Xiaowei, Du Yuefeng, et al. Dynamic simulation and high-speed photography experiment on corn-ear husking [J]. Transactions of the Chinese Society of Agricultural Engineering (Transactions of the CSAE), (2015), 31(6): 42-48.

[17] Zhang Zui, Xiao Hongru, Ding Wenqin, et al. Mechanism simulation analysis and prototype experiment of Lycium barbarum harvest by vibration mode [J]. Transactions of the Chinese Society of Agricultural Engineering (Transactions of the CSAE), (2015), 31(10): 20-28.

[18] Zhao Chengfa, Chen Yuqin, Hao Weifeng, et al. Effects of Dry-cured Ham Processing Technics on the Flavor Substance[J]. Journal of Anhui Agricultural Sciences, (2013), 41(9): 4082-4083. 
International Journal of Hybrid Information Technology

Vol. 10, No.2 (2017) 